\title{
A LITERATURA COMO ALTERNATIVA PARA PRÁTICAS DECOLONIAIS NO ENSINO DE INGLÊS: UM ESTUDO AUTOETNOGRÁFICO SOBRE EXPERIÊNCIAS DE UMA PROFESSORA DE ESTÁGIO SUPERVISIONADO
}

Fernanda Mota Pereira

Área de Inglês do Instituto de Letras da Universidade Federal da Bahia, Brasil. pmotafernanda@gmail.com

\begin{abstract}
Resumo. Este artigo aborda minhas experiências como docente do componente curricular Estágio Supervisionado I de Língua Inglesa entre 2012 e 2019 através da análise de planos de ensino. A análise objetivou descortinar propósitos e princípios que regem esse componente e articular o ensino de inglês à literatura sob os pressupostos da Linguística Aplicada Crítica. Para isso, este artigo valese da autoetnografia como pesquisa qualitativa, que permite a subjetividade e a imersão em experiências pessoais em uma mirada decolonial. O trançado teórico desenvolvido no artigo é uma demonstração e uma defesa da decolonialidade, que promove uma desierarquização na pesquisa científica, que privilegia o rigor do método em detrimento da pluralidade de saberes que emergem quando subjetividades são enunciadas. Os resultados demonstram que escolhas teóricas no planejamento do componente de Estágio Supervisionado I, inicialmente, eram guiadas por uma ênfase no método e em pressupostos teóricos de autores alinhados com a Colonialidade e mostram como princípios decoloniais se inserem no escopo teórico do componente gradualmente. Para isso, a literatura figura como um recurso profício no estabelecimento de práticas decoloniais no ensino de inglês.
\end{abstract}

Palavras-chave: Educação; Ensino de Inglês; Autoetnografia; Linguística Aplicada; Literatura.

\section{LITERATURE AS AN ALTERNATIVE TO DECOLONIAL PRACTICES IN ENGLISH LANGUAGE TEACHING: AN AUTOETHNOGRAPHIC STUDY ON EXPERIENCES OF A TEACHING PRACTICUM PROFESSOR}

\begin{abstract}
This article addresses my experiences as a professor of the Supervised English Teaching Practicum I course between 2012 and 2019 through the analysis of course descriptions. The analysis aimed to unveil the purposes and principles that guide this course and to articulate the teaching of English to literature under the assumptions of Critical Applied Linguistics. To this end, this article draws on autoethnography as qualitative research, which allows for subjectivity and immersion in personal experiences in a decolonial perspective. The theoretical fabric developed in the article is a demonstration and a defense of decoloniality that promotes the de-hierarchization in scientific research, which favors the rigor of the method over the plurality of knowledge that emerges when subjectivities are enunciated. The results demonstrate that the theoretical choices in the planning of the Supervised English Teaching Practicum I course were initially guided by an emphasis on methods and on theoretical assumptions of authors aligned with Coloniality. They also show that decolonial principles gradually fall into the theoretical scope of the course. For that, literature appears as a propitious resource in the establishment of decolonial practices in the teaching of English.
\end{abstract}

Keywords: Education; English teaching; Autoethnography; Applied Linguistics; Literature.

\section{INTRODUÇÃO}

Neste artigo, abordo experiências como docente do componente curricular Estágio Supervisionado I de Língua Inglesa. Nele, teço considerações sobre a transição de uma ênfase em conteúdos convencionais, que enfocavam o método, para pensar questões 
inseridas no campo da Decolonialidade (Walsh, 2018; Mignolo, 2018), tendo em horizonte as contribuições da literatura. Para isso, analisei, sob os pressupostos da pesquisa qualitativa (Méndez, 2013; Oliveira, 2008), os planos de curso do componente curricular supracitado que elaborei entre os anos de 2012 e 2019 e fiz um relato crítico sobre escolhas e transições. Nessas, a literatura figurou como um aporte protagonista por permitir acessar contextos culturais que escapam a eixos hegemônicos através do estudo de textos não canônicos.

O artigo está dividido em duas partes. A primeira apresenta a metodologia e os argumentos sobre a relação entre Linguística Aplicada e Literatura bem como a inserção no âmbito da Pesquisa Qualitativa e Autoetnográfica, tendo em horizonte a (de)colonialidade. Na segunda parte, analiso os planos de curso, acionando a memória sobre aulas que ministrei, e assinalo o caráter profícuo de usar a literatura em aulas de inglês.

\section{METODOLOGIA: DECOLONIZANDO O MÉTODO EM PESQUISA QUALITATIVA ATRAVÉS DA AUTOETNOGRAFIA}

A pesquisa que alicerça este artigo se insere no campo da Linguística Aplicada Crítica (Pennycook, 2001) e é de cunho qualitativo (Méndez, 2013) e autoetnográfico (Hughes; Pennington, 2017; Méndez, 2013). A articulação entre esses campos ocorre por se tratar de um estudo sobre a linguagem e seus usos, enfocando questões de (de)colonialidade no ensino de língua inglesa no âmbito de um componente curricular voltado à formação de professores, Estágio Supervisionado, sob uma perspectiva autoetnográfica, porque aciono a minha própria experiência como docente desse componente para tecer reflexões críticas. $O$ caráter qualitativo incide por se constituir de uma interpretação dos insumos da pesquisa ao invés de uma análise de caráter positivista com conclusões quantificadas e categóricas.

A Linguística Aplicada Crítica é o campo indisciplinar (Moita Lopes, 2006) em que se inserem as reflexões neste artigo em virtude do estudo sobre epistemologias subjacentes às opções metodológicas em Estágio Supervisionado I e que se referem também a concepções de língua, tendo em perspectiva implicações políticas e sociais. No que se refere à pesquisa qualitativa, também chamada interpretacionista, esta "defende o estudo do homem, levando em conta que o ser humano não é passivo, mas sim que interpreta o mundo em que vive continuamente." (Oliveira, 2008, p. 2)

Desse modo, nem sempre é adequado dispor de técnicas de medição numérica em pesquisas que envolvem sujeitos, pois há diversos fatores que interferem na investigação e que escapam 
à objetividade requerida por pesquisas quantitativas. Por esse motivo, elegi a abordagem qualitativa como parâmetro para esta pesquisa.

Apesar dos estudos que reconhecem o caráter lacunar da linguagem e a imprecisão da objetividade, em pesquisas acadêmicas, a impessoalidade sempre foi celebrada como um requisito para garantir cientificidade e validade. Mesmo nas pesquisas qualitativas, que primam pela interpretação em detrimento da medição dos dados, de acordo com Méndez (2013, p. 280, (tradução minha)), "[n]o período tradicional (início do século $X X$ ), os pesquisadores objetivavam apresentar um relato objetivo de suas experiências de campo." Neste período, que se inicia logo depois da guerra e se estende até a década de 1970, houve uma busca em alinhar a pesquisa qualitativa à quantitativa no que se refere à exatidão (Méndez, 2013).

Na mesma linha temporal, ao final da guerra fria e início do neoliberalismo, Aníbal Quijano cunhou o termo "colonialidade" (Mignolo, 2018, p. 106). A criação deste termo instaurou o processo de decolonialidade, porque, como afirma Mignolo (2018, pp. 106-107), "[a] colonialidade - o lado mais sombrio da modernidade ocidental - é um conceito decolonial e, portanto a âncora do pensamento e do fazer decolonial na prática do viver." Assim, a necessidade de decolonizar emergiu diante da constatação de que a colonialidade existe.

A decolonialidade contempla não só o conhecimento científico, mas, também, os mais diversos saberes, incluindo aqueles advindos de experiências pessoais. Com isso, o uso da primeira pessoa e da subjetividade foi resignificado. Ademais, é preciso considerar que a pretensa objetividade que se possa tentar estabelecer através de métodos científicos falha em atingir a "verdade", porque os dados são interpretados, passando, portanto, pelo crivo da subjetividade. Como afirmam Denzin e Lincoln (2000) apud Méndez (2013, p. 284, (tradução minha)), "“[a] realidade objetiva nunca pode ser capturada. Nós apenas sabemos uma coisa através de suas representações" e "Rasuro a palavra "representações" para insistir no uso do termo "interpretações" (p. 5). Assim, conclusões científicas sempre se pautam em interpretações, sobretudo quando se referem a algo que não pode ser mensurado, a exemplo de crenças, atitudes, questões identitárias, entre outros. Mesmo quando a precisão pode ser pretensamente alcançada, os métodos usados e a apresentação dos resultados são mediados por interesses, crenças e propósitos daqueles que os manipulam.

Para respaldar essa afirmação, aludo ao aparato científico usado no século XIX para asseverar a superioridade racial dos europeus, ancorado no Darwinismo e Mendelenismo 
(Blaut, 1992). O estabelecimento desses critérios foi marcado por forte narcisismo, pois os europeus que definiram parâmetros de superioridade foram aqueles classificados como superiores. O estabelecimento desses critérios não só elevou aqueles que os criaram a um status de privilégio como ainda rechaçou padrões de avaliação alheios aos seus. Essa configuração da ciência faz parte da história do colonialismo e da modernidade, sustentados pela colonialidade que orquestrou modos de saber e existir. Entre esses modos, destacamse, na produção do conhecimento, aqueles que se pautam na objetividade e na fidelidade ao método. Essa concepção de ciência desconsidera que qualquer pesquisa é atravessada pelo olhar do pesquisador, que, mesmo quando respaldado pelo distanciamento impresso pelo uso da terceira pessoa e pelos procedimentos de validade dos dados, é atravessado pela subjetividade. Embora essa subjetividade resvale inevitavelmente para a pesquisa, a voz do pesquisador, nos métodos voltados à objetividade, é suprimida. Uma das vantagens da autoetnografia é dessilenciar essa voz (Méndez, 2013).

É importante frisar que o discurso em primeira pessoa não é dotado de transparência. Essa não existe na primeira nem na terceira pessoa, porque qualquer discurso é constituído pela linguagem e esta nunca é transparente. Assim, se para Hughes e Pennington (2017, p. 753, (tradução minha)), "[a] autoetnografia representa um processo, produto, e possibilidade de aprender mais sobre um assunto que você presumivelmente conhece bem-você mesmo", o termo "presumivelmente" deve ser salientado, porque a linguagem é atravessada pelo contexto social e pode impor, por vezes, modos de expressão que escapam ao controle do sujeito que a usa. Essa impossibilidade de controlar a linguagem resulta do que Barthes (1978) definiu como o fascismo da língua. Nesse tocante, é necessário mencionar as censuras conscientes e inconscientes no processo de escrita, o uso da memória em cuja constituição há lacunas preenchidas, por vezes, pela ficcionalização, os desvios de interpretação estimulados por crenças, sentimentos e objetivos, entre outros fatores. Assim, mesmo quando o sujeito fala sobre si, esse texto não é fidedigno à experiência em um sentido positivista.

Aqueles mais arraigados ao positivismo podem perguntar, então, por que seria viável ter acesso a pesquisas qualitativas e autoetnográficas se elas não revelam a verdade sobre um determinado fenômeno. A resposta reside no mesmo argumento sobre o porquê de ser importante conhecer diversas culturas, histórias e experiências, que se refratam em miríades de modos de existir inapreensíveis pelos padrões daqueles que se debruçam sobre elas, assinalando a necessidade de decolonizar um modo de eleger o que importa conhecer e quem pode falar. 
A abertura da pesquisa qualitativa para a autoetnografia representa um avanço na valorização da experiência subjetiva como insumo para o conhecimento que não considera apenas os dados, mas também sentimentos, identidades, ideologias. Por esse motivo, a autoetnografia contempla diversos formatos de apresentação dos dados, que fogem a modelos convencionais, podendo figurar como um "poema, uma narrativa ou uma história" (Denzin, 1989; Connelly \& Clandinin, 1999; Nekvapil, 2003 citado em Méndez, 2013, p. 281, (tradução minha)). A abertura para esses gêneros é um convite para considerar textos como a literatura como fontes de questões culturais e sociais que podem servir para estudar sobre determinados contextos ou fenômenos. Tal abertura alinha-se também com a problematização nietzschiana da "verdade" como "busca metafísica platônica advinda do desconhecimento do processo de invenção implicado nas 'teias' de sentido que compõem o frágil e flexível território dos saberes." (Fabrício, 2006, p. 53). Com a autoetnografia e práticas decoloniais, a episteme ocidental se distancia do pensamento metafísico platônico que institui a verdade como um parâmetro inalcançável e, ao mesmo tempo, almejável, pois assinala que cada perspectiva constrói uma verdade, não sendo esta exterior ao sujeito e nem peremptória.

A problematização do dogmatismo científico também é extensiva ao método na autoetnografia. Não há uma forma determinada de colocá-la em prática, sobretudo na vertente da autoetnografia evocativa, que "objetiva a introspecção dos pesquisadores sobre um tópico particular para permitir aos leitores fazerem conexões com os sentimentos e experiências dos pesquisadores" (Méndez, 2013, p. 281, (tradução minha)). Foi esta a vertente da qual me vali para analisar os planos de curso do componente Estágio Supervisionado I de Língua Inglesa no período de 2012 a 2019. Nas análises, acionei minhas percepções, sentimentos, memórias e aprendizados que substanciaram e substanciarão minha prática docente e que espero que sirvam como reflexão, também, para professores deste componente curricular e estudantes de cursos de licenciatura. O produto desse estudo é uma narrativa subjetiva substanciada por teorias que trazem um olhar crítico sobre o componente curricular enfocado e minha prática docente. Nessa prática, destaco o papel da literatura para redesenhar os propósitos que orientaram a minha proposta pedagógica decolonial e farão parte das minhas futuras experiências de ensino.

\section{EXPERIÊNCIAS COM ESTÁGIO SUPERVISIONADO I DE LÍNGUA INGLESA: ARTICULAÇÕES ENTRE LINGUÍSTICA APLICADA CRÍTICA E LITERATURA}


Em "Literatura e $(m)$ ensino de língua estrangeira" (Mota, 2010), teci argumentos sobre a relação entre a linguística e a literatura a despeito da clássica divisão entre esses dois campos na área de Letras. Argumentei que, apesar dessa divisão, esses dois campos têm como ponto de interseção os signos verbais, que "por sua vez, são embebidos de marcas simbólicas que muito expressam sobre uma 'realidade cultural'." (Mota, 2010, p. 102).

Independentemente do contexto em que o professor se insere, as realidades culturais que compõem o repertório de experiências dos aprendizes são diversas e é imprescindível encontrar modos de abordar essa diversidade. Todavia, quando comecei a lecionar Estágio Supervisionado, enfatizei o ensino de estratégias e princípios pedagógicos voltados ao processo de aprendizagem da língua inglesa sem considerar as implicações políticas da educação. Enfoquei métodos, abordagens, elaboração de plano de aula, ensino de habilidades de fala, escrita, compreensão oral e leitura, avaliação bem como o ensino do inglês padrão em contraste com a diversidade linguística do inglês e aspectos interculturais. Esses dois assuntos finais não tiveram protagonismo nas discussões e foram abordados no final do semestre, havendo pouca reverberação das contribuições que eles poderiam ter para ampliar a visão intercultural dos estudantes e desconstruir preconceitos em relação às variedades do inglês usadas fora do eixo hegemônico.

Posso afirmar que, ao elaborar o plano de ensino de Estágio Supervisionado I de Língua Inglesa ao longo dos anos de 2012 a 2016, tive o objetivo de abordar o que era necessário para formar o professor de língua inglesa que se valeria de estratégias para desenvolvimento de fluência e acuidade no idioma com fins de atender aos parâmetros do que seria uma aula efetiva. Esses objetivos estavam em alinhamento com a ementa do curso, a saber: "[e]studo teórico-metodológico de língua inglesa, seleção de métodos e técnicas relativos às habilidades de ouvir, falar, ler e escrever, visando à construção de práticas pedagógicas para possíveis espaços de aprendizagem." (Universidade Federal da Bahia, 2005, p. 100) e o Conteúdo Programático: "[a]presentação e avaliação dos principais métodos de ensino/aprendizagem; estratégias de ensino/aprendizagem; planejamento de aulas; avaliação; relação professor/aluno/sala de aula; questões interculturais na sala de aula; microaulas." (Universidade Federal da Bahia, 2005, p. 100).

No primeiro semestre em que ensinei Estágio Supervisionado I, os conteúdos, de acordo com o meu plano de ensino, foram: método, abordagem, metodologia, currículo, técnicas/procedimentos, mitos sobre o ensino de inglês como língua estrangeira, reflexões 
sobre os propósitos de ser um professor de inglês, Método de Tradução e Gramática, Método Direto, Método Audiolingual, Cognitive Code Learning, Community Language Learning, Suggestopedia, The Silent Way, Total Physical Response, Natural Approach, Functional Syllabus, Abordagem Eclética, Método Comunicativo, Task-Based Language Teaching, Learner-Centered Instruction, Cooperative Learning, Interactive Learning, Content-Based Instruction, Humanistic Education and Experiential Learning, Negotiated Curricula, Construtivismo, Parâmetros Curriculares Nacionais para o Ensino Médio, planejamento de aulas, uso de filmes ou outras mídias em sala de aula, abordagem intercultural, ensino das quatro habilidades, ensino de inglês sem recursos e em salas com muitos alunos, leitura crítica, questões interculturais através da literatura e de filmes, o perfil do professor e o professor "engraçado", inglês padrão e ingleses mundiais, avaliação, múltiplas inteligências, uso de tecnologias em sala de aula, o desenvolvimento profissional do professor. Além disso, os estudantes assistiram ao filme Freedom Writers para terem um exemplo de proposta pedagógica de uma professora que pode ser considerada uma intelectual transformadora (Kumaravadivelu, 2003) e observarem as estratégias que ela usou para envolver a sua turma e tornar as aulas mais inspiradoras e significativas.

Os conteúdos permaneceram os mesmos no segundo semestre de 2012 e no primeiro de 2013. No segundo semestre de 2013, inseri dois conteúdos: o uso de projetos e o ensino de gramática. Essa inserção indica a minha preocupação em ampliar a efetividade das aulas que os estudantes ensinariam ao abordar o ensino de gramática, que é um dos assuntos contemplados mais comumente nas aulas de inglês da educação básica, especialmente em escolas públicas, e a tentativa de implementar uma modalidade diversa das aulas em moldes mais tradicionais ao convidar os estudantes a refletirem sobre o uso de projetos. No primeiro semestre de 2014, houve uma pequena variação em relação aos planos de curso anteriores com o acréscimo do assunto Ensino de Literatura e Inteligência Emocional. A inserção desse conteúdo sugere a finalidade de ampliar a relação entre ensino de língua inglesa e literatura. No segundo semestre de 2014 e primeiro de 2015, mantive os mesmos conteúdos e referências.

No segundo semestre de 2015, por sua vez, acrescentei a leitura de um dos capítulos de Pedagogia do Oprimido, de Paulo Freire, que tem tradução em inglês, e o conteúdo criatividade. A inserção de um dos capítulos do referido livro resultou da experiência de observação de aulas no componente curricular Estágio Supervisionado II de Língua Inglesa, em que os estudantes ministram aulas em uma escola pública de ensino médio. Em turmas 
em que os estudantes faziam o estágio, alguns aprendizes comentaram sobre a ausência de equidade na educação na rede pública e particular e problemas em suas comunidades que os impediam, muitas vezes, de irem ou permanecerem em sala de aula. Neste momento de minha atuação como professora de estágio supervisionado, observei que precisava ensinar questões sociais e culturais que preparassem os estudantes para lidar com situações em que esse tipo de assunto emergisse. Todavia, em virtude das demandas da turma, esse propósito se tornou secundário diante da necessidade de dar às aulas um caráter mais prático. Por esse motivo também, optei por usar textos do livro de Harmer (1998), cuja linguagem é simples e os capítulos apresentam exemplos práticos sobre os conteúdos teóricos.

Nos dois semestres de 2016, ensinei apenas Estágio Supervisionado II de Língua Inglesa e pude ter maior imersão no universo escolar. Com isso, passei a ponderar sobre a necessidade de estreitar a relação entre universidade e escola através, também, de outros componentes curriculares. Assim, no primeiro semestre de 2017, optei por ministrar um componente curricular de literatura, Teatro de Língua Inglesa. Nele, uma das atividades teve como propósito planejar estratégias para abordar as peças de teatro nas aulas de inglês da educação básica. Havia notado, nas experiências com Estágio Supervisionado II, que os estudantes não relacionavam os conteúdos dos componentes de literatura à sua prática pedagógica, em que as escolhas metodológicas estavam mais alinhadas com métodos centrados unicamente na língua (Kumaravadivelu, 2003). Com esse horizonte em tela, quando voltei a ensinar Estágio Supervisionado I, inseri no plano de curso do segundo semestre de 2017 um texto de minha autoria (Pereira, 2016), em que abordo o ensino despido de questões culturais e a ênfase excessiva na noção de língua como sistema e não como prática social e cultural e proponho estratégias didáticas pautadas em princípios interculturais.

Do que narrei até então, observo que, até 2017, o meu intuito principal era formar professores cujos objetivos fossem desenvolver as competências e habilidades de seus aprendizes para uso efetivo do idioma. Essa proposta alinha-se com reflexões teóricas e experiências com Estágio Supervisionado trazidas por autoras como Brito e Ribas (2018), em cujas considerações destaco alguns pontos caros à formação de professores, a saber: a noção de que o conhecimento não é estático, mas, sim, dinamicamente construído, a importância da contextualização, a desconstrução da dicotomia entre teoria e prática, o ensino em que a língua não é concebida como um fim em si, mas uma forma de "mediação" (Brito \& Ribas, 2018, p. 248). 
Esses pontos são facilmente identificados em livros basilares que figuram em programas de disciplina de Estágio Supervisionado. Entre alguns dos livros mais comumente usados nesse componente curricular, menciono Techniques and Principles in Language Teaching, de Larsen-Freeman (2008), em que a autora enfoca variados métodos e apresenta exemplos de sua aplicação.

É válido afirmar que o método se caracteriza como uma série de procedimentos elaborados idealmente para serem aplicados em variados contextos sem considerar suas especificidades. Essa caracterização do método converge com preceitos da Colonialidade (Quijano, 2010), pautada na noção de totalidade como se houvesse "uma e só uma lógica que governa o comportamento do todo e de todas e de cada uma das partes" (Quijano, 2010, p. 1414). Por analogia, o modelo que os defensores do método têm em horizonte é o da totalidade e ela é construída com base em parâmetros ocidentais. Em consonância com essa visão, segundo Mahmoodzadeh (2011, p. 1376, (tradução minha)), "Kumaravadivelu (2003b) aborda as emergências do colonialismo nos métodos predominantes de ensino de línguas e argumenta que 'os métodos usados em diferentes partes do mundo, por mais modificados que sejam, ainda aderem basicamente ao conceito colonial de método' (p. 541)." Para Kumaravadivelu (2003), a alternativa para o caráter generalizante dos métodos é o estabelecimento de uma proposta que prima pelas especificidades, configurada como macroestratégias (Mahmoodzadeh, 2011; Kumaravadivelu, 2003), abarcando princípios adaptáveis a variados contextos de forma não prescritiva.

Embora Kumaravadivelu (2003) apresente parâmetros que orientam o ensino de língua inglesa, entre eles, o parâmetro da possibilidade, que considera a noção de que o ensino pode ser um agente de manutenção da opressão ou de transformação social, em reta linha com o pensamento de Paulo Freire, ele não alude aos problemas a serem enfrentados contra a opressão e seus desdobramentos - o racismo, a homofobia, a misoginia, entre outras formas de preconceito. Diante dessa ausência e de um cenário social que requer o debate sobre esses preconceitos, percebi que o ensino de língua inglesa que se atém apenas a questões linguísticas falha ao não contemplar as práticas discursivas que silenciam grupos historicamente subalternizados. Com essa constatação, concluí que o ensino deveria se voltar à agenda da democratização do direito à fala não só da língua estrangeira, mas também do que a habilidade de falá-la permite propagar. 
Além disso, ao ensinar uma língua de matriz imperialista como o inglês, é ético trazer à cena questões sociais, raciais e de gênero que promovam uma compreensão da realidade social e que levem, inclusive, a refletir sobre quem, historicamente, tem o privilégio de acesso ao aprendizado de inglês e a uma educação emancipadora. No tocante à relação entre privilégio e educação, Leffa (2011) afirma que a educação espelha a discriminação, uma vez que são as pessoas pobres que constituem a maioria daqueles que frequentam a escola pública, considerada de qualidade aquém em relação às escolas particulares e onde a efetividade do ensino de inglês é menor. Se, para Leffa (2011), a questão é social, para mim, trata-se também de uma questão racial (Pereira, 2019), pois a maioria das pessoas que frequenta a escola pública é negra.

Em face da emergência dessas questões na educação, como trazer reflexões sobre a realidade social sem deixar em segundo plano o ensino do idioma? Que repertório os futuros professores poderiam usar em suas aulas para dilatar a percepção dos aprendizes sobre sua realidade e promover o pensamento crítico? Tendo essas perguntas em horizonte, no segundo semestre de 2018, optei por privilegiar teóricos do Sul Global e iniciar Estágio Supervisionado I com uma discussão sobre a língua inglesa e seu lastro de opressão em relação às línguas dos sujeitos que foram colonizados (Hooks, 1994). Além disso, o pensador indiano Kumaravadivelu (2003) teve um protagonismo na introdução às categorias principais de método e acrescentei mais textos de autores brasileiros. Essa mudança epistemológica teve o propósito de decolonizar o currículo que fora orientado, por muito tempo, por um referencial canônico. No primeiro semestre de 2019, enfatizei a temática racial no início do curso ao trazer textos de Hooks $(1994,2003)$ para discussão.

Para maior imersão em questões sociais, raciais, culturais, entre outras, privilegiei a articulação entre linguística aplicada crítica e literatura.

Enquanto aquela promove os insumos metodológicos necessários para pensar estratégias de ensino significativas e se ocupa de "questões críticas que têm relação com acesso, poder, disparidade, desejo, diferença e resistência" (Pennycook, 2001, p. 171, tradução livre), a literatura possibilita o acesso a contextos culturais que levam à identificação entre o pano de fundo social dos próprios aprendizes e aquele que envolve personagens, servindo como um exercício de imersão em uma história que, em um jogo especular, tem sempre muito a dizer sobre si ao descortinar cenas de vivências do outro. 
Exemplos de atividades para ensino de inglês no contexto brasileiro através da literatura estão reunidos em textos que escrevi (Mota, 2010; Pereira, 2017; Pereira, 2019) e precedem e/ou fazem parte do projeto de pesquisa Educação em Narrativas: Experiências em Contextos de Aprendizagem (Pereira, 2016) vigente desde 2016. Esse projeto nasceu do intuito de articular a Linguística Aplicada Crítica e a Literatura e mapear os sentidos da educação em textos literários de países do Norte e Sul Global.

Quando associadas à literatura, as questões concernentes à Linguística Aplicada Crítica promovem ao aprendiz o contato com realidades diferentes da própria, o que pode levar a um olhar ainda mais amplo e atento a essas realidades. Além disso, para Ghosn (2001), a literatura estimula a inteligência emocional, envolvendo os circuitos cerebrais relacionados à empatia com reflexos no desenvolvimento linguístico e no bem-estar dos aprendizes. Apesar de centrar suas reflexões em crianças, os argumentos de Ghosn (2001) também se aplicam a adultos.

Para além dos benefícios à inteligência emocional, o ensino através da literatura pode servir à construção de uma sociedade mais ética, o que se traduz em bem-estar comum e preservação das mais diversas formas de vida, com especial atenção àquelas que estão vulneráveis aos mecanismos de opressão. Ter acesso a histórias que descortinam situações de opressão é um primeiro passo para a emancipação em relação à Colonialidade e seus tentáculos, o capitalismo e o liberalismo (Quijano, 2010), que se erguem como sistemas de exploração e hierarquização. Assim, entre os textos literários que podem ser abordados em prol da conscientização e construção de uma sociedade com mais empatia e senso de ética, aqueles de autores pertencentes a grupos subalternizados historicamente são os mais profícuos.

É importante frisar que a decolonização de conhecimentos e práticas não é um processo simples. Walsh (2018) reconhece a impossibilidade de se atingir um ponto em que a Colonialidade não mais exista. Ela reforça, contudo, a possibilidade de fazer "fissuras" (Walsh, 2018, p. 82) nela como forma de permitir práticas decoloniais atentas à diversidade e ao respeito a paradigmas dos povos cuja cultura foi encapsulada, não obstante sua riqueza e pluralidade, sob o rótulo de outro. Esse outro é, de forma simplista, aquele que não é europeu. Para Mignolo (2018), somos responsáveis pela nossa emancipação, mas, quando somos professores, essa responsabilidade é ainda maior, pois usamos estratégias e lidamos com 
conteúdos que podem reafirmar ou deslocar a Colonialidade e que não se encerram na sala de aula, reverberando para a sociedade.

\section{CONCLUSÕES}

Neste artigo, revisitei conteúdos e escolhas epistemológicas que orientaram os meus planos de ensino de Estágio Supervisionado I de Língua Inglesa entre 2012 e 2019 e observei o quanto minha prática inicial estava dissociada de questões caras a uma sociedade que traz as marcas da desigualdade e dos preconceitos enredados por séculos de Colonialidade. Para abordar tais questões nas salas de aula de Estágio Supervisionado I, a literatura figurou como um recurso profícuo por permitir não apenas a imersão em realidades histórico-sociais e culturais, mas também pelas reverberações no desenvolvimento da inteligência emocional, que gera a empatia necessária para a construção de uma sociedade em que a diversidade seja respeitada, conhecida e celebrada.

Do que acionei e refleti na tessitura deste artigo, concluo que, nas minhas próximas experiências como docente de Estágio Supervisionado I de Língua Inglesa, adensarei as discussões sobre temáticas concernentes à realidade sociocultural do Brasil e de países onde o inglês é falado com atenção especial àqueles pertencentes ao Sul Global, articulando-as ao ensino desse idioma.

A ênfase no eixo Sul se pauta no que Achebe (2010) denomina como "equilíbrio de histórias" e que aqui denomino como equilíbrio de epistemologias. É preciso deslocar o lastro secular das epistemologias do Norte e fazer mais do que fissuras nelas: abrir possibilidades de pensar e viver a vida em sua pluralidade.

No âmbito dessa pluralidade, insere-se um modo de fazer pesquisa como a autoetnografia, que privilegia o caráter eloquente do que sempre se manteve em silêncio em nome de uma busca de objetividade e princípios positivistas: a voz do pesquisador. Assim, este artigo também teve como uma de suas metas contribuir para a consolidação da autoetnografia como abordagem qualitativa e enunciar a sua confluência com princípios decoloniais.

\section{REFERÊNCIAS}

Achebe, C. (2000) Home and Exile. New York: Anchor Books.

Barthes, R. (1978) Aula. Tradução Leyla Perrone-Moisés. São Paulo: Editora Cultrix.

Blaut, J. M. (1992). The Theory of Cultural Racism. Antipode: A Radical Journal of Geography. 23, 289-299. 
Disponível em: <http://www.columbia.edu/ Inp3/mydocs/Blaut/racism.htm>. Acesso em 15 fev. 2020.

Brito, C. C. de P. \& Ribas, F. C. (2018) Estágio Supervisionado de Língua Inglesa como espaço de (trans)formação de professores. Entrepalavras, 8(3), 244-263.

Fabrício, B. F. (2006) Linguística Aplicada como espaço de "desaprendizagem”: redescrições em curso. In: Moita Lopes, L. P. (Org.), Por uma Linguística Aplicada Indisciplinar (pp. 45-65). São Paulo: Parábola.

Ghosn, I. (2001). Nurturing Emotional Intelligence through Literature. English Teaching Forum, 39(1). Retrieved from: https://americanenglish.state.gov/files/ae/resource_files/01-39-1-c.pdf

Harmer, J. (1998). How to Teach English: an Introduction to the Practice of English Language Teaching. Essex: Addison Wesley Longman Limited.

Hooks, B. (1994). Language. In B. Hooks (Eds.), Teaching to Transgress: Education as the practice of freedom (pp. 167-1759. Routledge: New York.

Hooks, B. (2003). Teaching Community: a Pedagogy of Hope. New York: Routledge.

Hughes, S. A., \& Pennington, J. L. (2017). Autoethnography: Process, Product, and Possibility for Critical Social Research. Thousand Oaks: Sage Publications, Inc.

Kumaravadivelu, B. (2003). Beyond Methods: Macrostrategies for Language Teaching. New Haven: Yale University Press. Disponível em: http://www.yale.edu/yup/pdf/095732_front_1_2.pdf.

Larsen-Freeman, D. (2008). Techniques and Principles in Language Teaching. (2a ed.). New York: Oxford University Press.

Leffa, V. J. (2011) Criação de bodes, carnavalização e cumplicidade: considerações sobre o fracasso da LE na escola pública. In: Lima, D. C. de (Org.). Inglês na escola pública não funciona? Uma questão, múltiplos olhares (pp. 15-31). São Paulo: Parábola.

Mahmoodzadeh, M. (2011). The Quest for Resolving Second Language Teaching Dilemma: A Review of the Proposed Solutions during the Last Two Decades. Theory and Practice in Language Studies, 1(10), 13751382.

Méndez, M. (2013). Autoethnography as a research method: Advantages, limitations and criticisms. Colombian Applied Linguistics Journal, 15(2), 279-287. Disponível em:

<http://www.scielo.org.co/scielo.php?script=sci_arttext\&pid=S012346412013000200010\&lng=en\&tlng=en>.

Mignolo, W. (2018). What Does It Mean to Decolonize?. In: Mignolo, W., \& Walsh, C. (Eds.). On Decoloniality: concepts, analytics, praxis (pp. 106-134). Durham and London: Duke University Press.

Moita Lopes, L. P. (2006) Linguística Aplicada e Vida Contemporânea: Problematização dos Construtos que Têm Orientado a Pesquisa. In: L. Moita Lopes (Ed.), Por uma Linguística Aplicada Indisciplinar (pp. 85-107). São Paulo: Editora Parábola.

Mota, F. (2010). Literatura e(m) Ensino de Língua Estrangeira. Fólio - Revista de Letras, 2(1).

Oliveira, C. L. de. (2008). Um apanhado teórico-conceitual sobre a pesquisa qualitativa: tipos, técnicas e características. Travessias: Pesquisa em Educação, Cultura, Linguagem e Arte, 2(3).

Pennycook, A. (2001). Critical Applied Linguistics: a Critical Introduction. New Jersey: Lawrence Erlbaum Associates.

Pereira, F. M. (2016): From non-cultural to intercultural principles: a proposal for English classes in Brazilian public schools, Intercultural Education. Intercultural Education, 1, 1-10.

Pereira, F. M. (2019) Education and Literatura: Reflections on Social, Racial, and Gender Matters/ Educação e 
Literatura: Reflexões sobre Questões Sociais, Raciais e de Gênero. Salvador: EDUFBA.

Quijano, A. (2010). Colonialidade do Poder e Classificação Social. In: BOAVENTURA, S. S Meneses, M.P. (Orgs.) Epistemologias do Sul. São Paulo, Cortez Editora, p. 1243-2034.

UNIVERSIDADE FEDERAL DA BAHIA (2005). Projeto de Reestruturação Curricular do Curso de Letras da Universidade Federal da Bahia, Salvador.

Walsh, C. (2018) On Decolonial Dangers, Decolonial Cracks, and Decolonial Pedagogies Rising. In: MIGNOLO, Walter; WALSH, Catherine E (editors). On Decoloniality: Concepts, Analytics, Praxis. Durham and London: Duke University Press, p. 81-98. 